\title{
The case of a positive outcome in hyperacute amniotic fluid embolism
}

\begin{abstract}
Akylbek Tussupkaliyev, Svetlana Tuite
№2 Department of Obstetrics and Gynecology, $M$ Ospanov West Kazakhstan Medical University, Aktobe, Republic of Kazakhstan
\end{abstract}

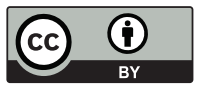

This work is licensed under a Creative Commons Attribution 4.0 International License

Received: 2018-12-27

Accepted: 2019-02-21

UDC: 616.1

\section{J Clin Med Kaz 2019; 1(51):61-64}

Corresponding Author: Svetlana Tuitebayeva, No

2 Department of Obstetrics and Gynecology, M.

Ospanov West Kazakhstan Medical University. Address:

3A, Altynsarin Street, 030002, Aktobe, Republic of

Kazakhstan. Tel.: +7(474) 605-79-62.

E-mail: ln2020@mail.ru a, Andrey Gaiday, Ulbolsyn Kairbaeva

\section{Abstract}

To date, in order to better understand the mechanisms for the development of terminal states associated with pregnancy, and to correctly assess the allowable costs in the organization of observation and intensive treatment, it is increasingly taking into account and analyzing not only deaths, but also cases of successful elimination from a critical condition, so called "near-miss cases". The given clinical case can be attributed to those. We observed a case of a positive outcome with an embolism of amniotic fluid of the lightning form, accompanied by cardiopulmonary shock with a double cardiac arrest, DIC - syndrome, postresuscitation disease. As practice shows, one of the most effective opportunities to shorten the way to success, is to use the experience of those, who have already traveled this way.

Keywords: pregnancy, amniotic fluid embolism, pregnancy complications

\section{ҚАҒАНАҚ СУЫМЕН ЭМБОЛИЯСЫНЫН ОН МӘНДІ НӘТИЖЕЛІ КЛИНИКАЛЫҚ ЖАҒДАЙ}

Тусупкалиев А.Б., Туйтебаева С.Б., Гайдай А.Н., Каирбаева У.Р.

№ 2 акушерия және гинекология кафедрасы, М. Оспанов атындағы Батыс Қазақстан мемлекеттік медицина университеті, Ақтөбе, Қазақстан Республикасы

\section{ТҰЖЫРЫМДАМА}

Қазіргі таңда жүктілікке байланысты терминальды жағдайлардың даму механизмін терең түсіну үшін, бақылау мен интенсивті емдеу мекемелерін, шағымдарды дұрыс бағалау үшін өлім жағдайларын ғана емес, сонымен қатар критикалық күйден шығару, яғни «жоғалтуға жақын» (near-miss) жағдайлар ескеріледі. Талқылап отырған клиникалық жағдайды осыған жатқызуға болады. Біз кағанақ суымен эмболиясының 2 рет жүрек тоқтауымен кардиопульмональді шокпен, ДВС - синдромымен, реанимациядан кейінгі ауруымен асқынған оң мәнді нәтижелі клиникалық жағдайды бақыладық. Тәжірибе көрсеткендей, жетістікке жетер жолды қысқартудың нәтижелі мүмкіндігі - бұл жолдан өткендердің тәжірибесін қолдану.

Негізгі сөздер: жүктілік, қағанақ суымен эмболиясы, жүктілік асқынулары

\section{СЛУЧАЙ ПОЛОЖИТЕЛЬНОГО ИСХОДА МОЛНИЕНОСНОЙ ФОРМЫ ЭМБОЛИИ ОКОЛОПЛОДНЫМИ ВОДАМИ}

Тусупкалиев А.Б., Туйтебаева С.Б., Гайдай А.Н., Каирбаева У.Р.

Кафедра акушерства и гинекологии №2, Западно-Казахстанский медицинский университет имени Марата Оспанова, Актобе, Республика Казахстан

\section{PEЗЮME}

На сегодняшний день для более глубокого понимания механизмов развития терминальных состояний, связанных с беременностью, и для правильной оценки допустимых издержек в организации наблюдения и интенсивного лечения, всё шире учитывают и анализируют не только случаи смерти, но и случаи успешного выведения из критического состояния, т.е. случаи, «близкие к потере» (near-тіss). Приведенный нами клинический случай можно отнести к таковым. Мы наблюдали случай положительного исхода при эмболии околоплодными водами молниеносной формы, сопровождающаяся кардиопульмональным шоком с двукратной остановкой сердечной деятельности, ДВС синдромом, постреанимационной болезнью. Как показывает практика, одна из наиболее результативных возможностей сократить путь к успеху - использовать опыт тех, кто этот путь уже прошёл.

Ключевые слова: беременность, эмболия околоплодными водами, осложнения беременности 


\section{Введение}

Эмболия околоплодными водами (ЭОВ) - критическое состояние, при котором амниотическая жидкость попадает в легочные сосуды и развивается симптомокомплекс шока смешанного генеза, приводящий к остановке сердечной деятельности, острой дыхательной недостаточности и ДВС [1].

По данным некоторых источников ЭОВ рассматривается как анафилаксия на биологически активные вещества. S.L. Clark предполагает, что различия в клинической манифестации ЭОВ связаны с разными вариантами воздействия антигенов и индивидуальным ответом каждого организма. Он также предложил называть эту патологию «анафилактоидным синдромом беременных», т.к. в некоторых наблюдениях ЭОВ похожа на анафилактический шок [2].

По данным некоторых источников ЭОВ встречается от 1 на 20000 до 1 на 80000 родов. Смертельный исход составляет от 80 до 90\%, что в структуре материнской смертности составляет $10 \%$. В настоящее время ЭОВ является одной из ведущих причин материнской смертности, что составляет существенную часть, а именно, в США - 7,6\%, в Австралии - 8\%, в Англии - 16\%, в России (2013) - 7,2\%. Поэтому возникает необходимость более глубокого изучения вопросов патофизиологии для усовершенствования методов лечения и улучшения исходов.

Патогенез ЭОВ остается не полностью изученным, а вопрос о том, как попадают околоплодные воды в сосудистую систему матери, остается открытым. ЭОВ может развиться в течение любого срока беременности или в раннем послеродовом периоде [4], при родовозбуждении, при невынашивании беременности [5] или при необходимости досрочного родоразрешения [6].

Непрогнозируемость данного осложнения обуславливает страх перед ним, поэтому все чаще принимаются попытки лучше понять патофизиологию с целью улучшения методов лечения и исходов. Несмотря на это, все еще нет полного понимания патофизиологии ЭОВ. Из-за редкости данного состояния, и ненадежности исследований на животных, большую часть информации во внесении ясности имеют описания клинических случаев.

Мы наблюдали случай положительного исхода при эмболии околоплодными водами молниеносной формы, сопровождающаяся кардиопульмональным шоком с двукратной остановкой сердечной деятельности, ДВСсиндромом, постреанимационной болезнью.

\section{Описание случая}

Пациентка Д., 26 лет поступила в городскую больницу с жалобами на излитие околоплодных вод. Соматически здорова.

Акушерский анамнез: беременность - данная первая. Беременность протекала гладко. По УЗИ в сроке 30 недель однократное обвитие пуповины вокруг шеи плода.

Припоступленииобщеесостояниеудовлетворительное. По органам без особенностей.

Акушерский статус: матка увеличена соответственно сроку беременности, не возбудима. Сердцебиение плода до 140 ударов в 1 минуту, ясное, ритмичное.

На зеркалах: подтекают светлые околоплодные воды.

Взяты анализы. Из них заслуживают внимания: в ОАК гемоглобин 81 г/л, лейкоциты 7,5-11,2-7,5-15,7х10/9/л (в динамике), гематокрит 26,7\%, свертываемость крови по
Сухареву 3 мин 20 сек, СОЭ 36 мм/ч. БАК, коагулограмма, ОАМ в пределах нормы.

Выставлен диагноз: Беременность 40 недель 1 день. Дородовый разрыв плодных оболочек. Составлен соответствующий план ведения.

На 1 сутки пребывания в стационаре самостоятельно началась регулярная родовая деятельность, переведена на территорию родильного зала. Отмечалась смена регулярной родовой деятельности ложными схватками в латентной фазе родов, после чего начата индукция родов путем в/в инфузии окситоцина по схеме. Через 2 часа началась регулярная родовая деятельность, в родах произведена эпидуральная анестезия. Во втором периоде при активных потугах в течении 30 минут отмечается отсутствии продвижения головки, осмотрена вагинально, выявлено асинклитическое вставление головки плода, выставлен диагноз “Обструктивные роды”. Решено произвести операцию кесарево сечение в экстренном порядке.

Произведена операция: лапаротомия по Джоел-Кохену. Кесарево сечение поперечным разрезом в нижнем маточном сегменте. Особенности операции: отмечалась placenta ceasarea. На 2 минуте за ножку из-за низкого расположения головки излечен живой доношенный ребенок женского пола, массой 3680,0 кг, ростом 54 см, с оценкой по шкале Апгар 9/10 баллов, отмечается небольшая родовая опухоль в области правой теменной кости.

После извлечения ребенка началась клиника молниеносной формы эмболии околоплодными водами (молниеносное апноэ, остановка сердечной деятельности; зрачки $\mathrm{D}=\mathrm{S}$, широкие, фотореакции нет, акроцианоз, пульсации на крупных сосудах не прослушиваются), были проведены меры расширенной сердечно-легочной реанимации и интенсивной терапии с положительным эффектом. АД 72/20 мм рт ст, пульс 98, SpO2 100\%.

Через 3 минуты произошла повторная остановка сердечной деятельности, асистолия. Возобновлены реанимационные мероприятия через 2 минуты после повторной остановки восстановлена сердечная деятельность. АД 81/20 мм рт. ст., пульс 61 уд. в минуту, $\mathrm{SpO} 2$ 100\%. Зрачки $\mathrm{D}=\mathrm{S}$, широкие, фотореакции нет.

Интраоперационно консилиум: учитывая удовлетворительный тонус матки и отсутствие признаков кровотечения и ДВС синдрома, решено объем операции ограничить кесаревым сечением.

Взяты анализы и проведены инструментальные исследования. Заслуживают внимания: ОАК: гемоглобин 68 г/л, тромбоциты 161,0х10/9/л, гематокрит 20,3\%, свертываемость крови по Сухареву 4 минуты 00 секунд.

БАК: общий белок 75 г/л, мочевина 5,2 ммоль/л, креатинин 80,0 ммоль/л, глюкоза 4,0 ммоль/л, Алат 17 мккат/л, Асат 36 мккат/л, общий билирубин 14,7 млмоль/л.

Коагулограмма: ПТИ 67,6\%, ТВ 23,1 сек, АЧТВ 45,0 сек, фибриноген 3,1 г/к.

ЭКГ: Ритм не равномерный положительный. ЭОС горизонтальная. Тахикардия ЧСС 140 уд. в минуту.

Родильница в операционной. Проведена мобилизация персонала. В послеоперационном периоде отмечается развитие ДВС-синдрома, анемии тяжелой степени, снижение тонуса матки: произведены гемотрансфузии СЗП (4 дозы) и эритроцитарной массы (2 дозы), начата утеротоническая терапия.

Повторно проведено ЭКГ: Суправентрикулярная тахикардия с ЧСС 195 ударов в минуту. Нормальное 
положение ЭОС. Смещение сегментов ST V3-V6.

Учитывая состояние женщины созван консилиум: продолжать контроль клинических и лабораторных данных, при продолжающемся кровотечении принять меры хирургического гемостаза.

Осмотр терапевта: Кардиогенный шок? Рекомендовано: повторная ЭКГ, консультация кардиолога, обзорная R-графия грудной клетки.

Повторный консилиум:

учитывая продолжающееся послеродовое кровотечение на фоне ДВС синдрома (имеет место коагулопатия по анализам (ПТИ 67,7, АЧТВ 75,0), из половых путей появились кровянистые выделения, производится лечение: перелито 1400,0 мл СЗП, эр.масса 550,0 мл, диурез сохранен) и неэффективности консервативной терапии по жизненным показаниям решено провести меры хирургического гемостаза, объем операции - решить интраоперационно.

Осмотр невролога: ДВС - синдром. Гипоксемия. Энцефалопатия тяжелой степени. Кома I степени. Отек головного мозга. Рекомендовано: противоотменная терапия, магний 25\% 200,0 мл в/в капельно, консультация профессора.

Через час после кесарева сечения произведена релапаротомия с участием сосудистого хирурга. Перевязка внутренних подвздошных артерий. Надвлагалищная ампутация матки без придатков. Дренирование брюшной полости. По вскрытии брюшной полости в рану предлежит сальник и петли кишечника. При ревизии органов малого таза матка бледно-розового цвета, дряблой консистенции, увеличена до 14-15 недель беременности, при наружном массаже матки тонус не восстанавливается. Интраоперационно консилиум: учитывая объем кровопотери, ДВС синдром, атонию матки решено провести перевязку внутренних подвздошных артерий с последующей надвлагалищной ампутацией матки без придатков. Моча по катетеру светлая, объем 500,0 мл. Кровопотеря 1050,0 мл. Общая кровопотеря 2500,0 мл.

Послеоперационный диагноз: срочные индуцированные оперативные роды. Дородовый разрыв плодных оболочек. Асинклитическое вставление головки плода. Эмболия околоплодными водами, молниеносная форма. Кардиопульмональный шок с остановкой сердечной деятельности. ДВС - синдром. Анемия тяжелой степени. Послеродовое кровотечение. ДВС - синдром. Релапаротомия. Перевязка внутренних подвздошных артерий. Надвлагалищная ампутация матки. Постреанимационная болезнь. Дренирование брюшной полости.

В послеоперационном периоде взяты анализы, проведены повторно инструментальные исследования: по анализам сохраняется постгеморрагическая анемия.

Повторный консилиум: С учетом анамнеза, характера и течения заболевания, у больной имеет место выраженная гипоксия головного мозга, не исключается эмболия мозговых сосудов на фоне эмболии околоплодными водами. Диагноз: Срочные оперативные роды. Дородовый разрыв плодных оболочек. Родовозбуждение окситоцином. Асинклитическое вставление. Нижнесрединная лапаротомия. Кесарево сечение. Эмболия околоплодными водами. Кардиопульмональный шок остановкой сердечной деятельности. ДВС синдром. Релапаротомия. Перевязка внутренних подвздошных артерий. Ампутация матки.
Постреанимационная болезнь. Рекомендовано: 1. Продолжить противоотечную терапию; нейропротенция; антикоагулянтная терапия, КТ головного мозга после стабилизации состояния с последующей МРТ головного мозга.

Лабораторно-инструментальные данные проведены в полном объеме.

Проконсультирована узкими специалистами: Окулист: Ангиопатия сетчатки; эндокринолог: данных за сахарный диабет не выявлено. Симптоматическая гипертензия. Контроль сахара в динамике.

Дальнейший мониторинг и интенсивная терапия продолжена в операционной. Проведена инфузионная, симптоматическая терапия. Гемотрансфузия одногруппной эритроцитарной массы, продленная ИВЛ. Дальнейшее лечение продолжено в ОИТ.

Консилиум: послеродовый период 2 сутки. Эмболия околоплодными водами. ДВС - синдром, перевязка внутренних подвздошных артерий с обеих сторон. Кардиопульманальный шок с остановкой сердечной деятельности. Постреанимационный синдром. Острая диффузная гипоксическая энцефалопатия. Кома 1-2 степени. Отек головного мозга. Рекомендовано: контроль лабораторных данных, контроль АД, пульса, температуры тела, диуреза, УЗИ брюшной полости, малого таза, ЭХО ЭКГ сердца, консультация окулиста, КТ головного мозга и внутренних органов после стабилизации состояния, бак. посевы из дренажа, из зева, дыхательной трубки, бак. посев мочи, кровь на стерильность, ежедневная перевязка, продолжить комплексное интенсивное лечение в условиях ОРИТ.

Родильница переводится в многопрофильную больницу в отделение интенсивной терапии и реанимации. При поступлении в полном объеме проведены лабораторноинструментальные исследования, консультации узких специалистов. Тяжесть состояния подтверждена результатами проведенных исследований.

Консилиум: послеродовый период 2 сутки. Эмболия околоплодными водами. ДВС-синдром, перевязка внутренних подвздошных артерий с обеих сторон. Кардиопульмональный шок с остановкой сердечной деятельности. Постреанимационный синдром. Острая диффузная гипоксическая энцефалопатия. Кома 1-2 степени. Отек головного мозга. Рекомендовано: УЗИ органов брюшной, плевральной полостей, контроль клинико-биохимических анализов, антибактериальная терапия, бак. анализы в работе, амбро 2,0 2 раза в/в, консультация физиотерапевта, ингаляция + ЛФК, антианемическая терапия, коррекция КЩС, фраксипарин под контролем коагулограммы, симптоматическая терапия, нейропротекция, альдарон 100 мг, тригрим 5 мг, перевязка раны.

Проведены лечебные и диагностические мероприятия в полном объеме.

На 22 сутки в связи с улучшением состояния выписана из стационара для дальнейшего амбулаторного наблюдения.

Заключение гистологического исследования удаленной матки: Очагово-рассеянный эндомиометрит c преимущественной воспалительной инфильтрацией в нижнем сегменте. Очагово-рассеянный хориоамниодецидуит. 


\section{Обсуждение}

На сегодняшний день для более глубокого понимания механизмов развития терминальных состояний, связанных с беременностью, и для правильной оценки допустимых издержек в организации наблюдения и интенсивного лечения, всёшире учитывают и анализируют не только случаи смерти, но и случаи успешного выведения из критического состояния, т.е. случаи, «близкие к потере» (near-miss) [8]. Приведенный нами клинический случай можно отнести к таковым. Взаимосвязь между множеством факторов риска обладает низкой положительной прогностической ценностью для выявления причин развития ЭОВ.

Мы считаем, что терапия эмболии околоплодными водами была успешной, с тяжелым симптомокомплексом, описанным выше, и при отсутствии указаний на другие причины, были соблюдены основные и известные принципы диагностики и стандарты оказания высококвалифицированной, как акушерскогинекологической, так и реанимационной помощи пациентке.
В приведенном нами клиническом случае обращает на себя внимание молниеносность клинических проявлений, что еще раз заставляет проявлять настороженность к каждой роженице, в частности при родоразрешении оперативным путем, что само по себе является фактором риска ЭОВ.

В рутине профессиональных обязанностей, не стоит забывать, что любое физиологическое течение родов, может превратиться в патологическое. Настороженность к женщине должна быть соблюдена на всех этапах начиная со сбора анамнеза и заканчивая послеродовым периодом.

Как показывает практика, одна из наиболее результативных возможностей сократить путь к успеху использовать опыт тех, кто этот путь уже прошёл.

Disclosures: There is no conflict of interest for all authors.

Patient informed consent: obtained.

\section{Литература}

1. Clinical Protocol of the Ministry of Health of the Republic of Kazakhstan dated "December 27, 2017 Protocol No. 36 «Amniotic fluid embolism» [in Russian]

2. Clark SL, Hankins GDV, Dudley DA, et al. Amniotic fluid embolism: analysis of a national registry. Am J Obstet Gynecol. 1995; 172:1158-1167. https://doi.org/10.1016/0002-9378(95)91474-9

3. Milovanov A.P., Kiryushenkov P.A., Shmakov R.G., et al. Placenta maternal hemostasis regulator. [in Russian]. Obstet Gynecol. 2001; 3(3-5).

4. A.P. Milovanov, R.G. Shmakov, V.M. Sidelnikov [in Russian]. Relationship of the morphological parameters of the placenta with the coagulation potential of the blood. Mother and Child: Tez. report V ROS. forum. M. 2003; 137-138.

5. Serov V.N., Sukhikh G.T., Baranov I.I., Pyregov A.V., Tyutyunnik V.L., Shmakov R.G. Emergency conditions in obstetrics: a guide for doctors [in Russian]. GEOTAR Mmedia. 2011; 3:784.

6. McDonnell N. J., Percival V., Paechc M. J. Amniotic fluid embolism: a leading cause of maternal death yet still a medical conundrumю Int. J. Obstet. Anesth. 2013; 22:329-336. https://doi.org/10.1016/j.ijoa.2013.08.004

7. I.I. Kukarskaya. Near-miss monitoring: sharing experience [in Russian]. Status Praesens. 2014:4(21).

How to cite this article: Akylbek Tussupkaliyev, Svetlana Tuitebayeva, Andrey Gaiday, Ulbolsyn Kairbaeva. The case of a positive outcome in hyperacute amniotic fluid embolism [in Russian]. J Clin Med Kaz. 2019; 1(51):61-64 